\title{
Novel electrochemical synthesis of copper oxide nanoparticles decorated graphene- $\beta$-cyclodextrin composite for trace-level detection of antibiotic drug metronidazole
}

\author{
Vijayalakshmi Velusamy a,*, Selvakumar Palanisamy ${ }^{\mathrm{a}, \mathrm{b}}$, Thangavelu Kokulnathan ${ }^{\mathrm{c}}$, Shih-Wen Chen ${ }^{\mathrm{b}}$, \\ Thomas C.K. Yang ${ }^{\mathrm{b}, *}$, Craig E. Banks ${ }^{\mathrm{d}}$, Sumit Kumar Pramanik ${ }^{\mathrm{e}}$ \\ ${ }^{a}$ Division of Electrical, Electronic Engineering, School of Engineering, Manchester Metropolitan University, Manchester M1 5GD, United Kingdom \\ ${ }^{\mathrm{b}}$ Department of Chemical Engineering and Biotechnology, National Taipei University of Technology, No. 1, Section 3, Chung-Hsiao East Road, Taipei 106, Taiwan \\ ${ }^{\mathrm{c}}$ Electroanalysis and Bioelectrochemistry Lab, Department of Chemical Engineering and Biotechnology, National Taipei University of Technology, No. 1, Section 3, Chung-Hsiao \\ East Road, Taipei 106, Taiwan \\ ${ }^{\mathrm{d}}$ School of Science and Environment, Manchester Metropolitan University, Chester Street, Manchester M1 5GD, United Kingdom \\ ${ }^{\text {e } C S I R-C e n t r a l ~ S a l t ~ E ' ~ M a r i n e ~ C h e m i c a l s ~ R e s e a r c h ~ I n s t i t u t e, ~ B h a v n a g a r ~} 364$ 002, India
}

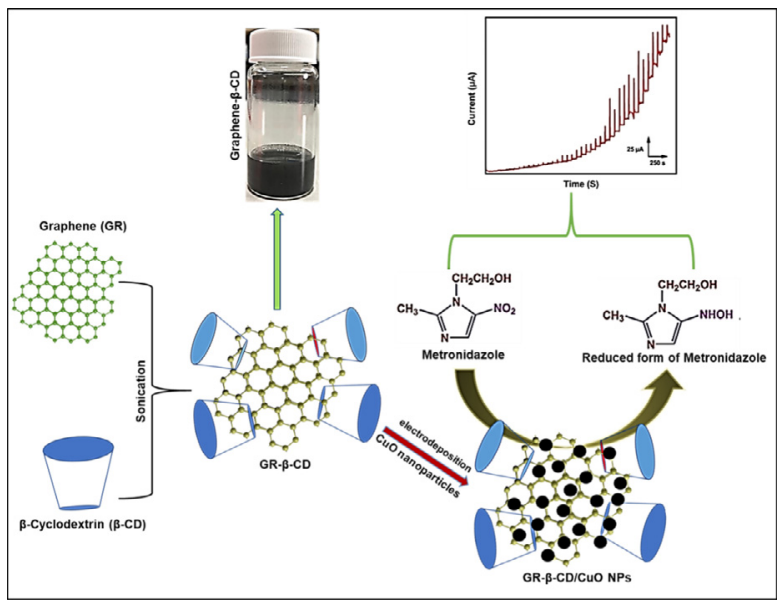

\section{A R T I C L E I N F O}

Article history:

Received 29 March 2018

Revised 20 June 2018

Accepted 21 June 2018

Available online 22 June 2018

\section{Keywords:}

Graphene

$\beta$-cyclodextrin

$\mathrm{CuO}$

Electrochemical synthesis

\begin{abstract}
A B S T R A C T
Over the past decades, the synthesis of inorganic and organic nanocomposites has received much attention in the range of fields including electroanalysis of organic chemicals. In this regard, we have prepared copper oxide nanoparticle (CuO NPs) decorated graphene/ $\beta$-cyclodextrin (GR- $\beta$-CD) composites using a simple electrochemical methodology, where the CuO NPs are electrodeposited on GR- $\beta$-CD composite modified electrodes. A stable GR- $\beta-C D$ composite was prepared by sonication of GR in $\beta-C D$ aqueous solution. As-prepared GR- $\beta-\mathrm{CD} / \mathrm{CuO}$ NPs composites were characterized by the high-resolution scanning electron microscopy, X-ray diffraction, and Raman spectroscopy. Cyclic voltammetry results reveal that the GR- $\beta-C D / C u O$ NPs composite modified electrode exhibits an excellent catalytic activity and lower reduction potential towards the electrochemical detection of metronidazole (MTZ) over other modified electrodes including GR, GR- $\beta-C D$, and CuO NPs. Under optimized conditions, amperometry was used for
\end{abstract}

\footnotetext{
* Corresponding authors.

E-mail addresses: V.Velusamy@mmu.ac.uk (V. Velusamy), ckyang@mail.ntut.edu.tw (T.C.K. Yang).
} 
Chemical sensor Metronidazole the determination of MTZ using GR- $\beta-C D / C u O$ NPs composite modified electrodes. The response of MTZ using the composite electrodes was linear over the range from 0.002 to $210.0 \mu \mathrm{M}$. This sensor showed the lowest limit of detection of $0.6 \mathrm{nM}$ and was much lower than the previously reported MTZ sensors. In addition, the sensor is highly sensitive, selective and durable in the presence of a range of potentially interfering electroactive compounds.

\section{Introduction}

Recent advancements of graphene-based composites have gained much attention in different applications including electrocatalysis [1]. Graphene (GR) has been widely known as a building block of all graphitic carbon forms, has a high theoretical surface area, mechanical strength and electrochemical activity over other carbon materials such as carbon nanotubes and C60 [2,3]. However, the stability of GR is poor in aqueous solutions due to the strong $\pi-\pi$ stacking of individual GR sheets into graphite [4]. Henceforth, the different nano or micro materials including, but not limited to carbon nanomaterials [5,6], metal/metal alloy nanoparticles [7,8], supramolecular adducts [9], conducting polymer $[10,11]$ and metal oxides $[12,13]$ have all been used to prevent the $\pi-\pi$ stacking of GR sheets. Furthermore, these GR based composites have shown an improved surface area and electrochemical activity over than of pristine GR. The GR based composites have also been used as an advanced electrode material for detection of toxic environmental pollutants in real systems [14-18]. Different polymer and nanomaterial supports have been used with GR to improve the dispersion ability and catalytic activity of GR. More recently, we have used $\beta$-cyclodextrin ( $\beta$-CD) as a suitable dispersing agent for GR [19], which has dramatically improved the dispersion ability of GR in aqueous solution and prevent the re-stacking of GR sheets. Despite the exciting characteristics of $\beta-C D$ (hydrophobic inner cavity and a hydrophilic exterior) that enables to form the stable composite with GR. In addition, the intercalation of unique properties of $\beta-C D$ can enhance the catalytic activity of the GR. On the other hand, cupric oxide $(\mathrm{CuO})$ has received significant attention in the scientific community due to its large surface to volume ratio and high catalytic activity and non-toxicity $[20,21]$. Despite these unique properties, $\mathrm{CuO}$ has been widely used in different applications including sensors [22], photocatalysis [23] and energy storage [24]. In comparison to other available methods, the electrodeposition of $\mathrm{CuO}$ has distinct advantages such as low operating temperatures and cost-effectiveness. In addition, the electrodeposition method can control the growth, morphology, structure, and orientation of $\mathrm{CuO}$. Consequently, the integration of $\mathrm{CuO}$ with GR- $\beta$-CD composite could further improve the electrocatalytic activity of GR. Hence, in the present work, we have prepared CuO nanoparticle (CuO NPs) decorated GR- $\beta-C D$ composites via a simple electrochemical methodology.

Metronidazole (MTZ) is an antibiotic drug and has been widely used for the treatment of pelvic inflammatory disease, endocarditis, and bacterial vaginosis $[25,26]$. However, the overdose and long-term use of MTZ will result in leucopenia, neutropenia, increased risk of peripheral neuropathy, and central nervous system toxicity [27]. Therefore, the accurate monitoring of MTZ concentrations in real samples is of significant interest. To date, the range of analytical methods has been used for the determination of MTZ such as high-performance liquid chromatography (HPLC), gas chromatography-mass spectrometry (GC-MS), liquid chromatography-mass spectrometry (LC-MS) and electrochemical methods. In comparison with available spectrophotometry and chromatography traditional methods [28], electrochemical methods are found to be simple and cost-effective and offer more sensi- tivity and selectivity towards the determination of MTZ [29]. Unmodified graphite or glassy carbon electrodes are not suitable for determination of MTZ due to their low sensitivity, low selectivity and fowling or drifting of electrochemical signals. Hence, different micro or nanomaterial-modified electrodes have been used for the sensitive and selective detection of MTZ [30]. In the present work, the as-prepared GR- $\beta-\mathrm{CD} / \mathrm{CuO}$ NPs composite was used as a sensitive and lower potential electrode material for detection of MTZ for the first time. In addition, a simple electrochemical method was used for the decoration of $\mathrm{CuO}$ NPs on pristine GR$\beta-C D$ composite modified glassy carbon electrode (GCE).

\section{Experimental section}

\subsection{Materials}

Graphene nanoflakes (thickness $=8 \mathrm{~nm}$ ) and metronidazole (analytical standard) were purchased from Sigma-Aldrich. $\beta$-cyclodextrin, $\mathrm{CuCl}_{2}, \mathrm{KCl}$ and other chemicals were obtained from Sigma-Aldrich. All chemicals were of standard analytical grade and used as received. The stock solutions and electrolyte solutions were prepared using double distilled (DD) water without any further purification. The $\mathrm{pH} 7.0$ (phosphate buffer) was used as a supporting electrolyte, and was prepared using $0.1 \mathrm{M} \mathrm{Na}_{2} \mathrm{HPO}_{4}$ and $\mathrm{NaH}_{2} \mathrm{PO}_{4}$ in DD water. The $\mathrm{pH}$ of the solution was adjusted using either $0.1 \mathrm{M} \mathrm{NaOH}$ or diluted $\mathrm{H}_{2} \mathrm{SO}_{4}$. DC150H Ultrasonicator from Taiwan Delta New Instrument Co. Ltd. with an operating frequency of $40 \mathrm{kHz}$ and ultrasonic power output of $150 \mathrm{~W}$ was used for sonication.

\subsection{Characterization methods}

High-resolution scanning electron microscopic (SEM) images were taken by Hitachi S-4300SE/N High-Resolution Schottky Analytical VP electron microscope. The elemental spectral analysis (EDS) of the GR- $\beta-C D / C u O$ NPs composite was analyzed using BRUKER AXS elemental analyzer with Hitachi S-4300SE/N HighResolution Schottky Analytical VP SEM. The Zetasizer Nano ZS90 (Malvern Panalytical) was used for the Zeta potential and hydraulic diameter measurements. Raman spectrum was acquired by a Dong Woo 500i Raman spectrometer from Korea. X-ray diffraction (XRD) analysis was performed using XPERT-PRO diffractometer from PANalytical B.V., The Netherlands.

\subsection{Electrochemical measurements}

Cyclic voltammetry and amperometry experiments were performed using $\mathrm{CH} 750 \mathrm{~A}$ electrochemical workstation from $\mathrm{CH}$ Instruments, USA. GR- $\beta-\mathrm{CD} / \mathrm{CuO}$ NPs composite modified GCE (the geometric surface area $=0.8 \mathrm{~cm}^{2}$ ) was used as a working electrode, and saturated $\mathrm{Ag} / \mathrm{AgCl}$ and a platinum wire were used as the reference and auxiliary electrodes, respectively. The electrochemical measurements were carried out at room temperature in an $\mathrm{N}_{2}$ atmosphere unless otherwise stated. 


\subsection{Sensor fabrication}

First, GR- $\beta-C D$ composites were prepared via our previous reported methodology [19]. Briefly, $5 \mathrm{mg}$ of GR nanoflakes were added into $\beta$-CD ( $\left.5 \mathrm{mg} \mathrm{mL}^{-1}\right)$ aqueous solution via sonication of $\sim 30 \mathrm{~min}$ at room temperature. $8 \mu \mathrm{L}$ of the as-prepared GR- $\beta-\mathrm{CD}$ composite were dropped onto pre-cleaned GCE and dried at room temperature. For the electrodeposition of $\mathrm{CuO} \mathrm{NPs,} 0.1 \mathrm{M} \mathrm{CuCl}_{2}$ and $0.1 \mathrm{M} \mathrm{KCl}$ were prepared in a $20 \mathrm{~mL}$ electrochemical cell and the $\mathrm{pH}$ of the solution adjusted to 11 using $\mathrm{NaOH}$. Then, the GR- $\beta-\mathrm{CD}$ composite modified GCE was immersed into the electrochemical cell, and 20 cyclic voltammetry cycles were performed in the potential sweeping from +1.1 to $-0.7 \mathrm{~V}$ at a scan rate of $50 \mathrm{mV} / \mathrm{s}$ [31]. The resulting CuO NPs decorated GR- $\beta$-CD composite modified GCE was dried in an air oven for $5 \mathrm{~min}$. For comparison, $\mathrm{CuO}$ NPs modified electrodes was prepared by a similar procedure without GR- $\beta-C D$ composite. The GR and GR- $\beta-C D$ composite modified GCEs were prepared without electrodeposition of CuO NPs, where $8 \mu \mathrm{L}$ of GR and GR- $\beta-C D$ composite dispersions were drop coated on GCE. The GR dispersion was prepared by dispersing of $5 \mathrm{mg}$ GR nanoflakes in $1 \mathrm{~mL}$ dimethylformamide for sonication about $30 \mathrm{~min}$. All fabricated modified electrodes were stored at room temperature under a dry condition when not in use.

\section{Results and discussion}

\subsection{Characterization of $G R-\beta-C D / C u O N P s$ composite}

The surface morphology of as-prepared materials were characterized by SEM, and the SEM images of as-prepared CuO NPs, GR, GR- $\beta-C D$ and GR- $\beta-C D / C u O$ NPs composite are shown in Fig. 1. The SEM image of electrodeposited $\mathrm{CuO}(\mathrm{A})$ shows a uniform distribution of nano-sized particles, and the diameter of nanoparticles were in the range between 40 and $90 \mathrm{~nm}$. The SEM of GR (B) shows its unique ultra-thin sheet-like morphology, while the GR- $\beta-C D$ composite $(C)$ shows a crumbled morphology wherein the GR nanosheets were enfolded by $\beta-C D$ [19]. On the other hand, a uniform sized CuO NPs are clearly visible on the crumbled surface of the GR- $\beta-C D$ composite from the SEM images of Fig. 1D. Furthermore, the diameter of the electrodeposited CuO NPs on GR- $\beta-C D$ composite was in the range from 45 to $80 \mathrm{~nm}$, and is more consistent with the SEM image of CuO NPs. The strong film-forming ability of GR and the host-guest interaction of $\beta-C D$ with CuO NPs are resulting into the formation of homogenous morphology and less agglomeration of $\mathrm{CuO}$ NPs on GR- $\beta$-CD composite. The EDS was used to confirm the presence of copper, carbon, and oxygen in GR- $\beta-\mathrm{CD} / \mathrm{CuO}$ NPs composite. As shown in Fig. $2 \mathrm{~A}$, the strong signal of carbon, oxygen and copper was observed for the EDS of GR- $\beta$ $\mathrm{CD} / \mathrm{CuO}$ NPs composite. The result confirms the presence of carbon, oxygen and copper in GR- $\beta-\mathrm{CD} / \mathrm{CuO}$ NPs composite. The Zeta potentials of $\mathrm{CuO}$ NPs and GR- $\beta-\mathrm{CD} / \mathrm{CuO}$ NPs composite was measured to study the stability and charge of the synthesized CuO NPs in $\mathrm{pH}$ 7.0. The obtained Zeta potential distribution results are shown in Fig. 2B and C. The Zeta potential of the electrodeposited $\mathrm{CuO} \mathrm{NPs}$ was $+2.2 \mathrm{mV}$, which indicates that the $\mathrm{CuO}$ NPs are slightly positively charged in $\mathrm{pH}$ 7.0. However, the Zeta potential of GR- $\beta-\mathrm{CD} / \mathrm{CuO}$ NPs composite was found to be $-34.5 \mathrm{mV}$, which reveals the negatively charged nature of the fabricated composite in $\mathrm{pH}$ 7.0. It worthy to note that the CuO NPs are highly stable on the GR- $\beta-C D$ composite in $\mathrm{pH} 7.0$ rather than $\mathrm{CuO}$ NPs in $\mathrm{pH}$ 7.0. The dynamic light scattering measurements shows that the average hydraulic diameter of pristine $\mathrm{CuO}$ NPs and $\mathrm{CuO}$ NPs on GR- $\beta-C D / C u O$ NPs composite was $117.1 \mathrm{~nm}$ (97.3\% intensity) and $90.6 \mathrm{~nm}$ (99.2\% intensity), respectively. The observed hydraulic diameter of CuO NPs is higher than those observed in SEM (Fig. 1A and D), which shows the agglomeration of CuO NPs in $\mathrm{pH}$ 7.0. However, the GR- $\beta$-CD composite improved the stability of $\mathrm{CuO}$ NPs and prevented the agglomeration of NPs in $\mathrm{pH}$ 7.0.

XRD and Raman spectroscopy was also used to confirm the formation of the GR- $\beta-C D / C u O$ NPs composite and purity of utilized GR. Fig. $3 A$ depicts the XRD pattern of as-prepared GR- $\beta-C D / C u O$ NPs composite. The diffraction pattern shows the main characteristic peaks for $\left(\begin{array}{lll}0 & 0 & 2\end{array}\right)$ plane centered of GR at $2 \theta=22.6^{\circ}$ and a weak peak at $2 \theta=40^{\circ}$ for crystal plane for GR [32]. Five main
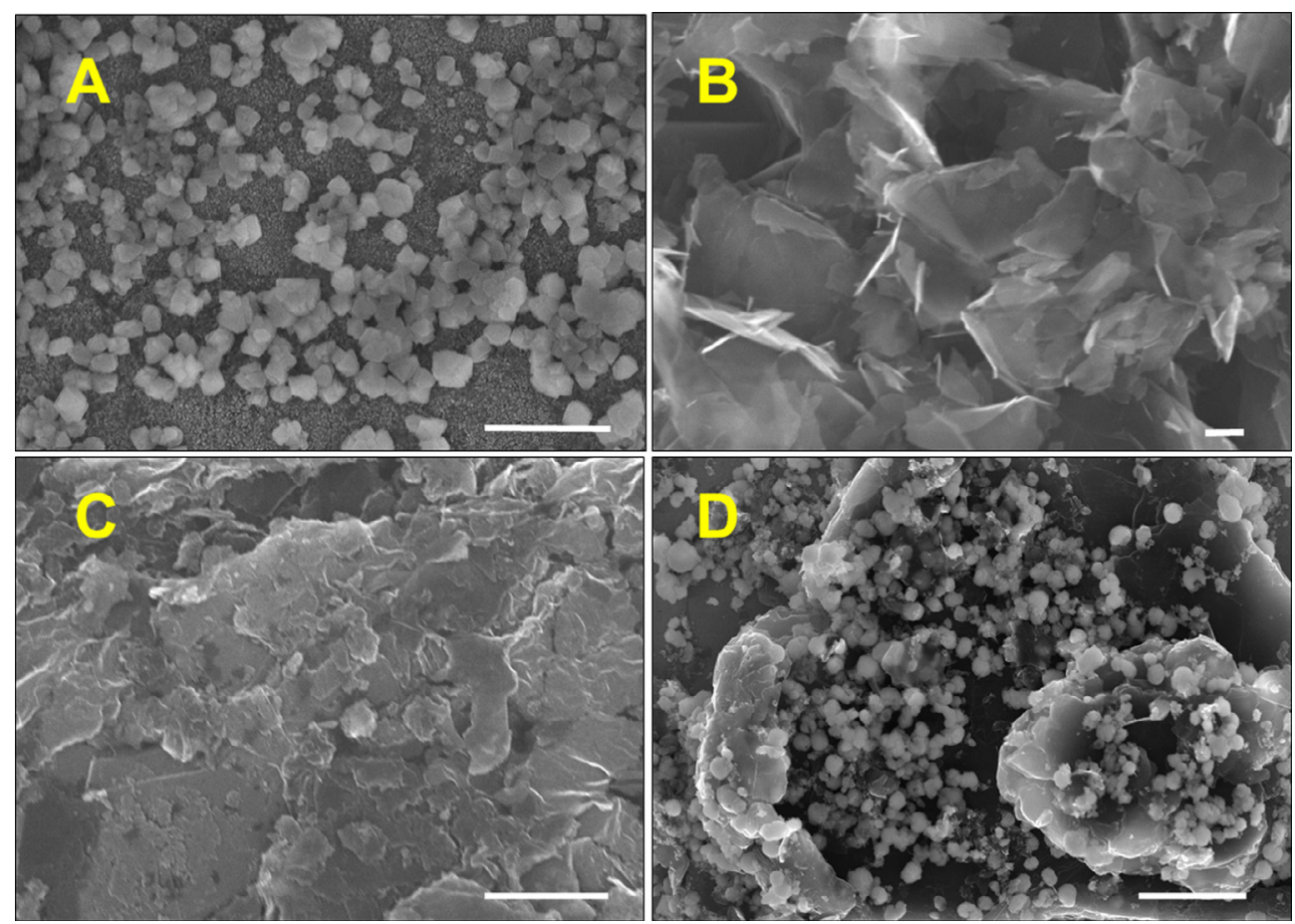

Fig. 1. High-resolution SEM images of CuO NPs (A), GR (B), GR- $\beta-C D(C)$ and GR- $\beta-C D / C u O$ NPs composite (D). Scale bar $=1 \mu \mathrm{m}$. 

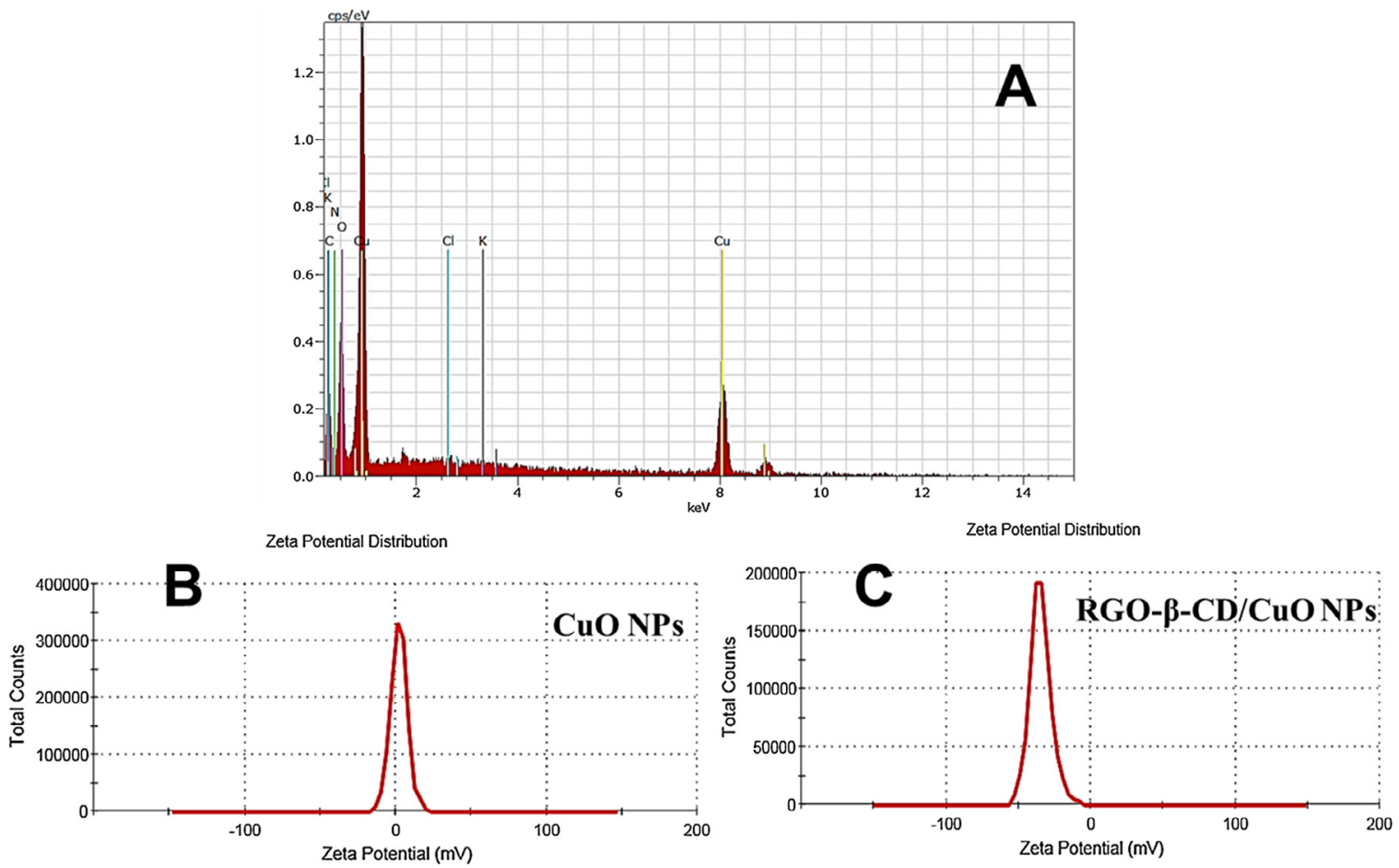

Fig. 2. (A) EDS of as-prepared GR- $\beta-\mathrm{CD} / \mathrm{CuO}$ NPs composite. Zeta potential distribution for CuO NPs (B) and GR- $\beta-\mathrm{CD} / \mathrm{CuO}$ NPs composite (C) in pH 7.0.
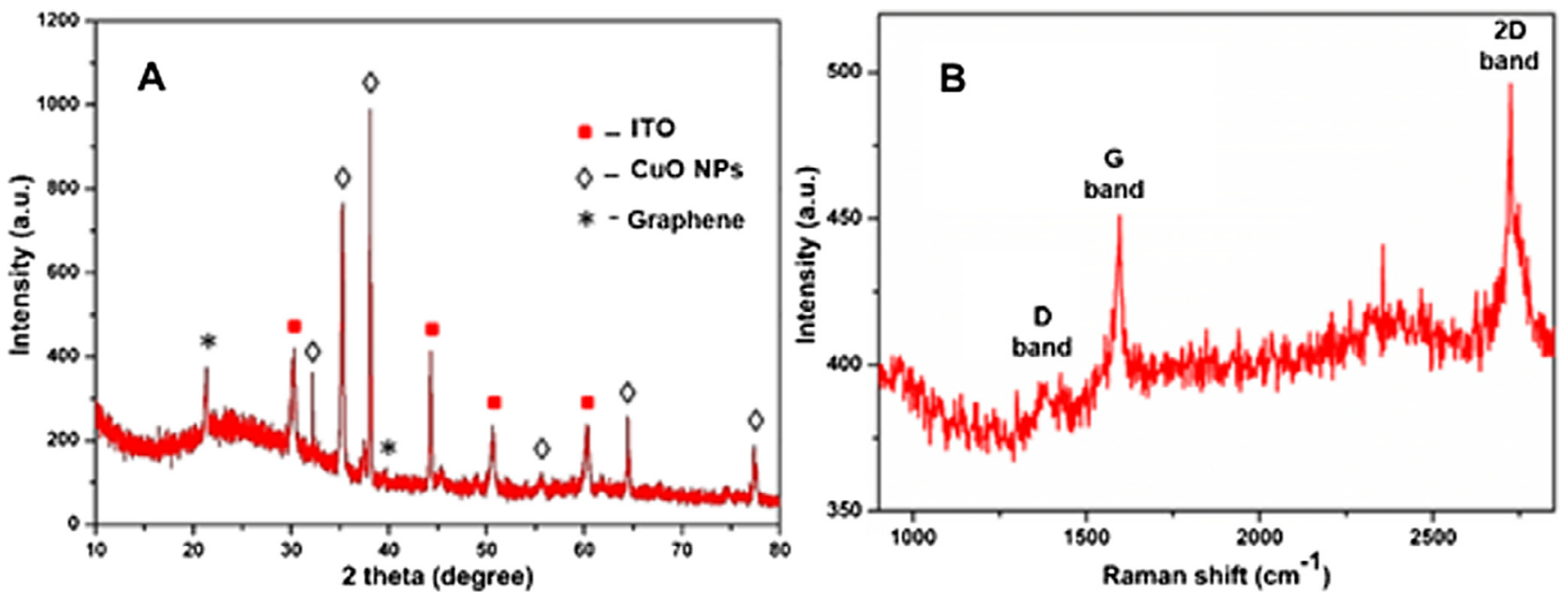

Fig. 3. (A) XRD pattern and Raman spectrum (B) of GR- $\beta-C D / C u O$ NPs composite.

characteristic peaks of $\mathrm{CuO}$ appeared at $32.7^{\circ}, 36.1^{\circ}, 38.6^{\circ}, 54.4^{\circ}$, and $65.3^{\circ}$ corresponding to Miller indices ( $\left.\begin{array}{lll}1 & 1 & 0\end{array}\right),\left(\begin{array}{lll}0 & 0 & 2\end{array}\right),\left(\begin{array}{lll}1 & 1 & 1\end{array}\right)$, $\left(\begin{array}{lll}0 & 2 & 0\end{array}\right)$ and $\left(\begin{array}{lll}2 & 2 & 0\end{array}\right)$, respectively [33]. The characteristic peak at $73.5^{\circ}$ is due to the reflections of ( 311 ) crystal plane of $\mathrm{Cu}_{2} \mathrm{O}$. The other reflection peaks are due to the presence of base indium tin oxide (ITO) electrode. Raman spectroscopy was also used to study the defects and purity of utilized GR in the composite and corresponding Raman spectrum is shown in Fig. 3B. The Raman spectrum GR shows the two distinct characteristic peaks in 1580 and $2721 \mathrm{~cm}^{-1}$, is resulting from the presence of $G$ and $2 D$ band of graphene $[34,35]$. The $G / 2 D$ intensity ratio was 0.9 , which shows the utilized GR contain few-layered GR, which is consistent with our previous report [36].

\subsection{Electrochemical behavior of MTZ at different modified electrodes}

Cyclic voltammetry was used to evaluate the electrochemical behavior of MTZ at different modified electrodes. The electrochemical behavior of different electrodes such as unmodified GCE, and GR, GR- $\beta-C D$, CuO NPs and GR- $\beta-C D / C u O$ NPs composite modified GCEs were studied in $\mathrm{pH} 7.0$ containing $50 \mu \mathrm{M}$ MTZ. The cyclic voltammetry experiments were performed over the potential range of 0.2 to $-1.0 \mathrm{~V}$ at a scan rate of $50 \mathrm{mV} / \mathrm{s}$. As shown in Fig. 4A, the bare (curve a) and CuO NPs (curve b) modified electrodes show a distinct reduction peak at -0.786 and $-0.768 \mathrm{~V}$ for the presence of MTZ. The reduction peak is attributed to the direct electrochemical reduction of the nitro group of MTZ to the 

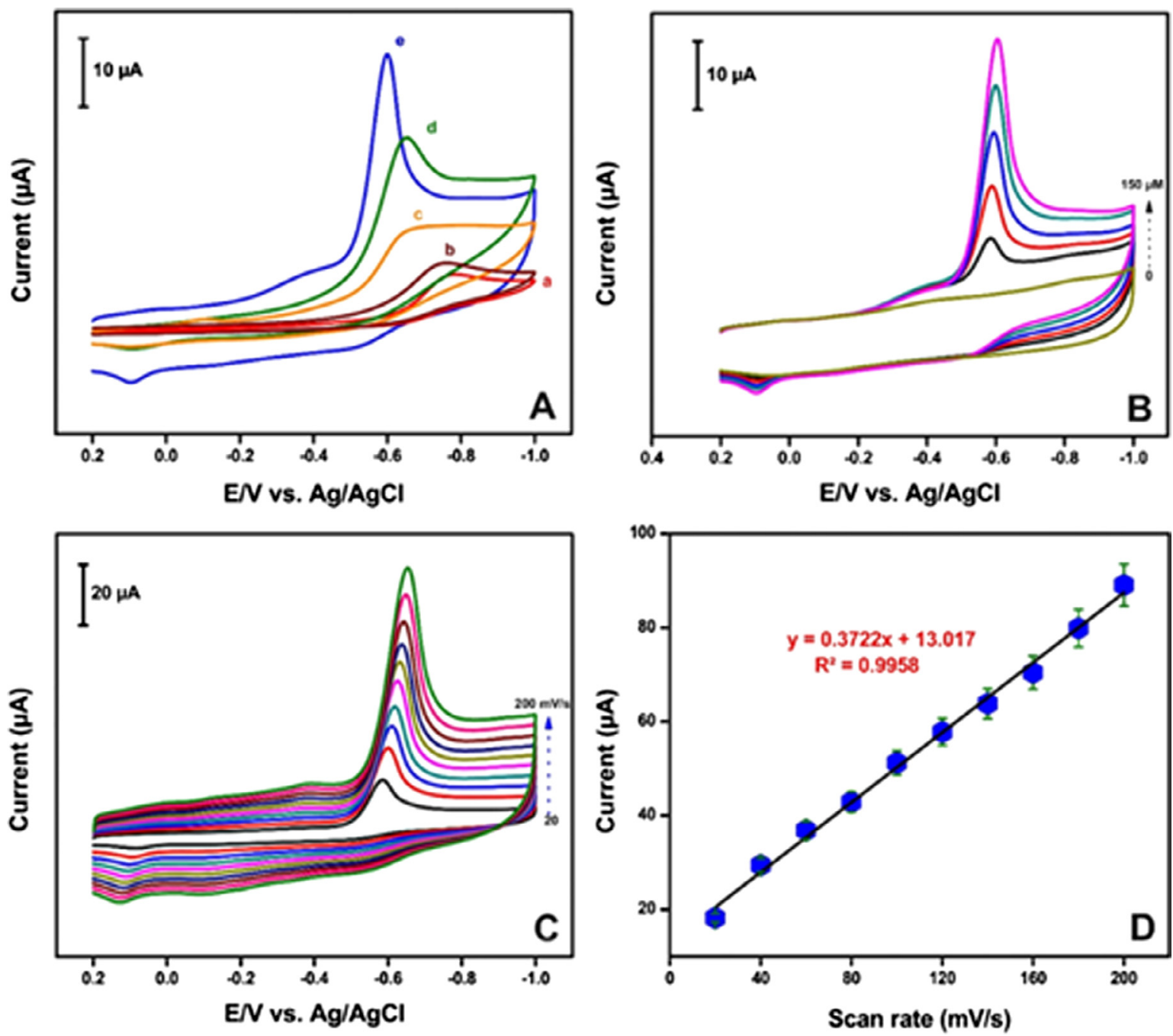

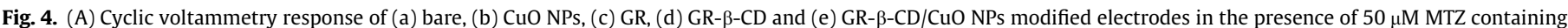

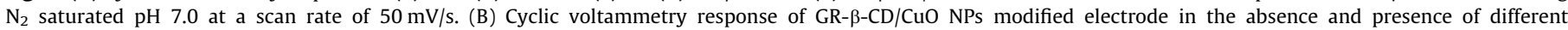

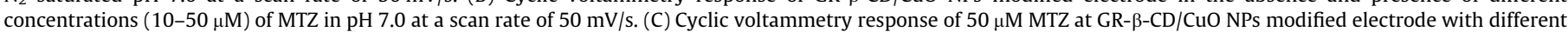
scan rates $(20-200 \mathrm{mV} / \mathrm{s})$ in $\mathrm{pH}$ 7.0. (D) The calibration plot of peak current vs. scan rate.

corresponding hydroxylamine. The reduction peak/signal of the MTZ is observed to be significantly enhanced using the GCE modified with GR (curve c). In addition, the reduction peak potential is observed to decrease to $-0.642 \mathrm{~V}$ from $-0.786 \mathrm{~V}$, and is observed to be 144 and $126 \mathrm{mV}$ lower than that of the bare and CuO NPs modified GCEs. The result shows that the electro-reduction ability of MTZ enhanced in GR modified electrode and is due to the larger surface area and high electron conducting nature of GR. On the other hand, the reduction peak current response to MTZ further enhanced (curve d) upon introduction of $\beta-C D$ with GR (GR- $\beta-C D$ modified electrode), which is due to the unique combined properties of GR (higher surface area) and $\beta-C D$ (high-adsorption ability). However, the reduction peak potential of MTZ at GR- $\beta-C D$ electrode found same as observed at GR modified electrode. The result clearly shows that the enhanced reduction peak current is clearly due to the high adsorption capability of $\beta-C D$ towards MTZ. The GR- $\beta-C D / C u O$ NPs composite modified electrode (curve e) shows 1.2 , and 3 fold enhanced current response to MTZ than GR- $\beta-C D /$ and GR modified electrodes. In addition, the reduction potential of MTZ at GR- $\beta-\mathrm{CD} / \mathrm{CuO}$ NPs composite modified electrode appears at $-0.596 \mathrm{~V}$. The observed reduction peak potential of MTZ at GR$\beta-\mathrm{CD} / \mathrm{CuO} \mathrm{NPs}$ composite modified electrode was $48 \mathrm{mV}$ lower than GR and GR- $\beta$-CD modified electrodes. The enhanced current response and lower reduction potential of MTZ at GR- $\beta-C D / C u O$ NPs composite modified electrode is possibly due to the presence of combined unique properties (high surface area and adsorption ability) of GR- $\beta-C D$ and $\mathrm{CuO}$ NPs. The result also confirms that GR- $\beta-C D / C u O$ NPs composite modified electrode can be used for the sensitive and lower potential detection of MTZ over the other modified electrodes such as CuO NPs, GR, and GR- $\beta-\mathrm{CD}$ composite.

\subsection{Effect of scan rate and $\mathrm{pH}$}

Cyclic voltammetry was used to explore the electrocatalytic ability of the GR- $\beta-C D / C u O$ NPs composites towards the sensing of MTZ. Fig. 4B shows the cyclic voltammetry response of GR- $\beta$ $\mathrm{CD} / \mathrm{CuO}$ NPs composite modified GCE in $\mathrm{N}_{2}$ saturated $\mathrm{pH} 7.0$ in the absence and presence $(10-50 \mu \mathrm{M})$ of MTZ at a scan rate of $50 \mathrm{mV} / \mathrm{s}$. In the absence of MTZ, GR- $\beta-\mathrm{CD} / \mathrm{CuO}$ NPs composite modified electrode did not show any obvious response, which indicates that the composite modified electrode is electrochemically inactive in $\mathrm{pH} 7.0$ at this scanned potential window. Whereas, a welldefined reduction peak was observed at $-0.592 \mathrm{~V}$ for the presence of $10 \mu \mathrm{M}$ MTZ. The reduction peak current response increases with 
the further additions of MTZ into the $\mathrm{pH}$ 7.0. The result authenticates that GR- $\beta-\mathrm{CD} / \mathrm{CuO}$ NPs composite modified electrodes have a useful electrocatalytic activity towards the reduction of MTZ. To understand the electrochemical behavior of MTZ at GR- $\beta-C D /$ $\mathrm{CuO}$ NPs composite modified electrode, the effect of scan rate was studied using cyclic voltammetry. Fig. $4 \mathrm{C}$ shows the cyclic voltammetry response of GR- $\beta-\mathrm{CD} / \mathrm{CuO}$ NPs composite modified electrode in $50 \mu \mathrm{M}$ MTZ containing pH 7.0 at different scan rates from 20 to $200 \mathrm{mV} / \mathrm{s}$. It can be seen that the reduction peak current response of MTZ increases with increasing the scan rate from 20 to $200 \mathrm{mV} / \mathrm{s}$. In addition, a notable shift in the reduction peak potential of MTZ was observed upon increasing the scan rate from 20 to $200 \mathrm{mV} / \mathrm{s}$. As shown in Fig. 3D, the scan rate was linearly proportional to the cathodic peak current response of MTZ with the correlation coefficient $\left(R^{2}\right)$ of 0.9958 . The result confirms that the electrochemical behavior of MTZ at the composite modified electrode was typically adsorption-controlled electrochemical process [36].

The effect of $\mathrm{pH}$ was studied using the cyclic voltammetry, and it can provide useful information to calculate the number of electrons and protons involved in the electrochemical reduction. Fig. $5 \mathrm{~A}$ shows the cyclic voltammetry response of $\mathrm{GR}-\beta-\mathrm{CD} / \mathrm{CuO}$ NPs composite modified electrode in $50 \mu \mathrm{M}$ MTZ containing various $\mathrm{pH}$ at a scan rate of $50 \mathrm{mV} / \mathrm{s}$. It can be seen that a welldefined reduction peak was observed for MTZ in each $\mathrm{pH}$ and the reduction peak shifted towards negative direction upon increasing the $\mathrm{pH}$ from 7.0 to 11.0 . The positive shift in reduction peak was observed when the $\mathrm{pH}$ was decreasing $\mathrm{pH}$ 7.0-3.0. The phenomenon indicates that the protons were involved in the reduction of MTZ. A linear plot has made for peak current versus $\mathrm{pH}$, and corresponding calibration plot is shown in Fig. 5B. It can be seen that the reduction peak potential of MTZ had a linear relationship with the $\mathrm{pH}$, and the slope was 0.9912. Fig. 5B also confirmed that a maximum reduction peak current response of MTZ was obtained at $\mathrm{pH}$ 7.0. One can see that the reduction peak current of MTZ decreased when the $\mathrm{pH}$ was below or above $\mathrm{pH} 7.0$ (blue denotation). The result also confirms that $\mathrm{pH} 7.0$ is an optimum for more sensitivity and hence pH 7.0 was used for further experimental studies. The possible electrochemical reduction mechanism of MTZ at the GR- $\beta-C D / C u O$ NPs composite modified electrode is shown in Fig. 6.

\subsection{Amperometric determination of MTZ}

Amperometry was used for the quantification of MTZ using the GR- $\beta$-CD/CuO NPs composite modified electrode. Rotating disc electrode (RDE) with a surface area of $0.8 \mathrm{~cm}^{2}$ was used for amperometric measurements. Amperograms of the composite electrode for MTZ was obtained in a constantly stirred (900 RPM) pH 7.0 at a working potential of $-0.6 \mathrm{~V}$. Fig. $7 \mathrm{~A}$ shows the typical amperometric i-t response of GR- $\beta-C D / C u O$ NPs composite modified RDE for different concentration additions of MTZ $(2 \mathrm{nM}-210.0 \mu \mathrm{M})$ into the $\mathrm{pH}$ 7.0. It can be seen that a sharp amperometric response was observed for the addition of 2, 10, 50, 100, 500, $1000 \mathrm{nM}$ of MTZ (first 6 amperometric curves) into the $\mathrm{pH} 7$ and the response current increases with increasing the addition of MTZ concentration (5 and $10 \mu \mathrm{M})$. The amperometric response current increases with the addition of MTZ from $2 \mathrm{nM}$ to $210.0 \mu \mathrm{M}$, and the response time of the sensor was $3 \mathrm{~s}$. The result demonstrates that $\mathrm{GR}-\beta-\mathrm{CD} / \mathrm{CuO} \mathrm{NPs}$ composite modified electrode has fast electrocatalytic reduction towards MTZ. As shown in Fig. 7B, the amperometric response of the GR- $\beta-C D / C$ OO NPs composite modified electrode was linear over the concentration of MTZ from $2 \mathrm{nM}$ to $210.0 \mu \mathrm{M}$ with the $\mathrm{R}^{2}$ of 0.9969 . The limit of detection (LOD) of the sensor was
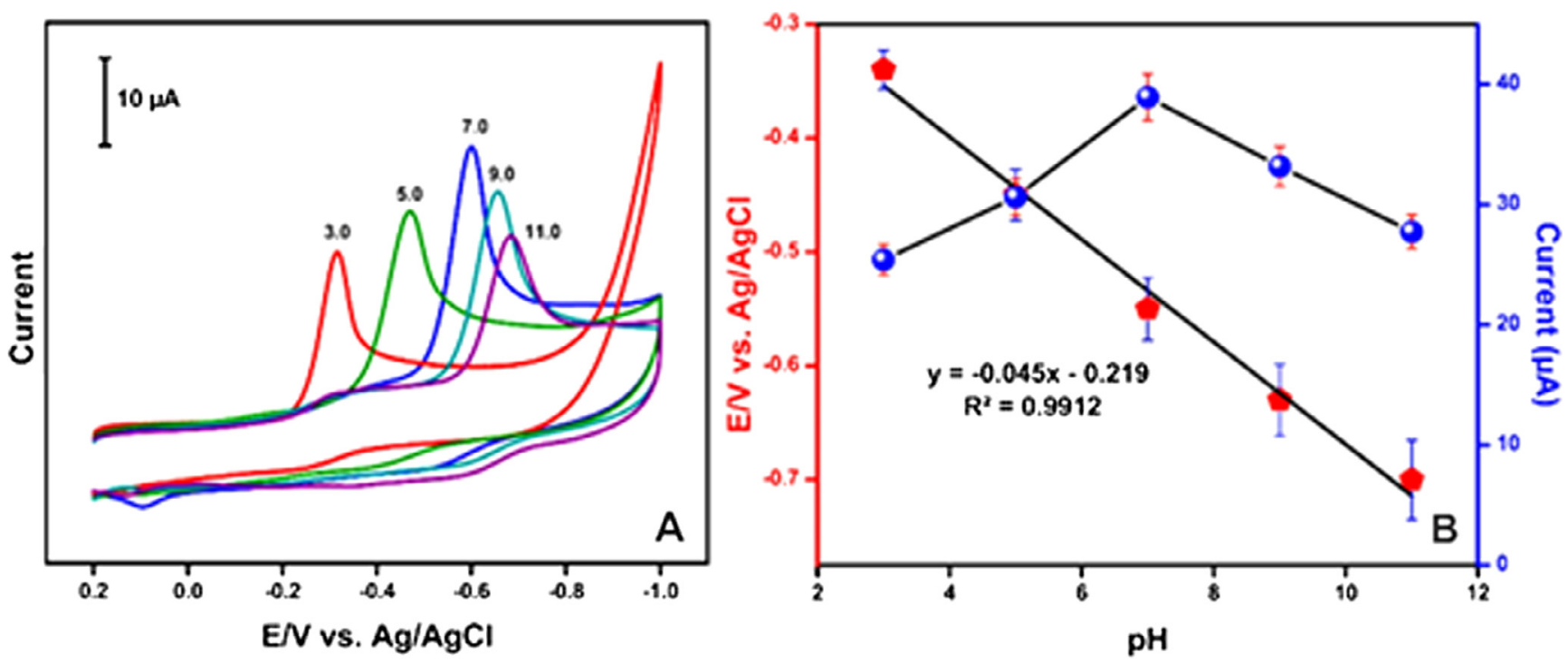

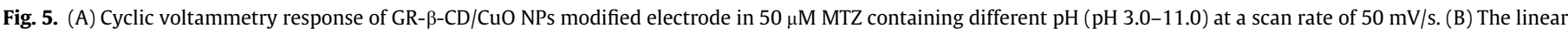

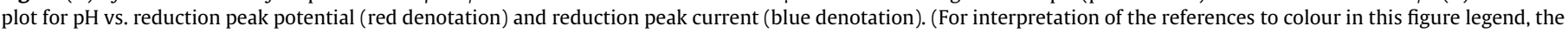
reader is referred to the web version of this article.)<smiles>[CH+][I+]=CCn1c([N+](=O)[O-])cnc1C</smiles>

Fig. 6. Possible electrochemical reduction mechanism of MTZ at GR- $\beta-C D / C u O$ NPs composite. 

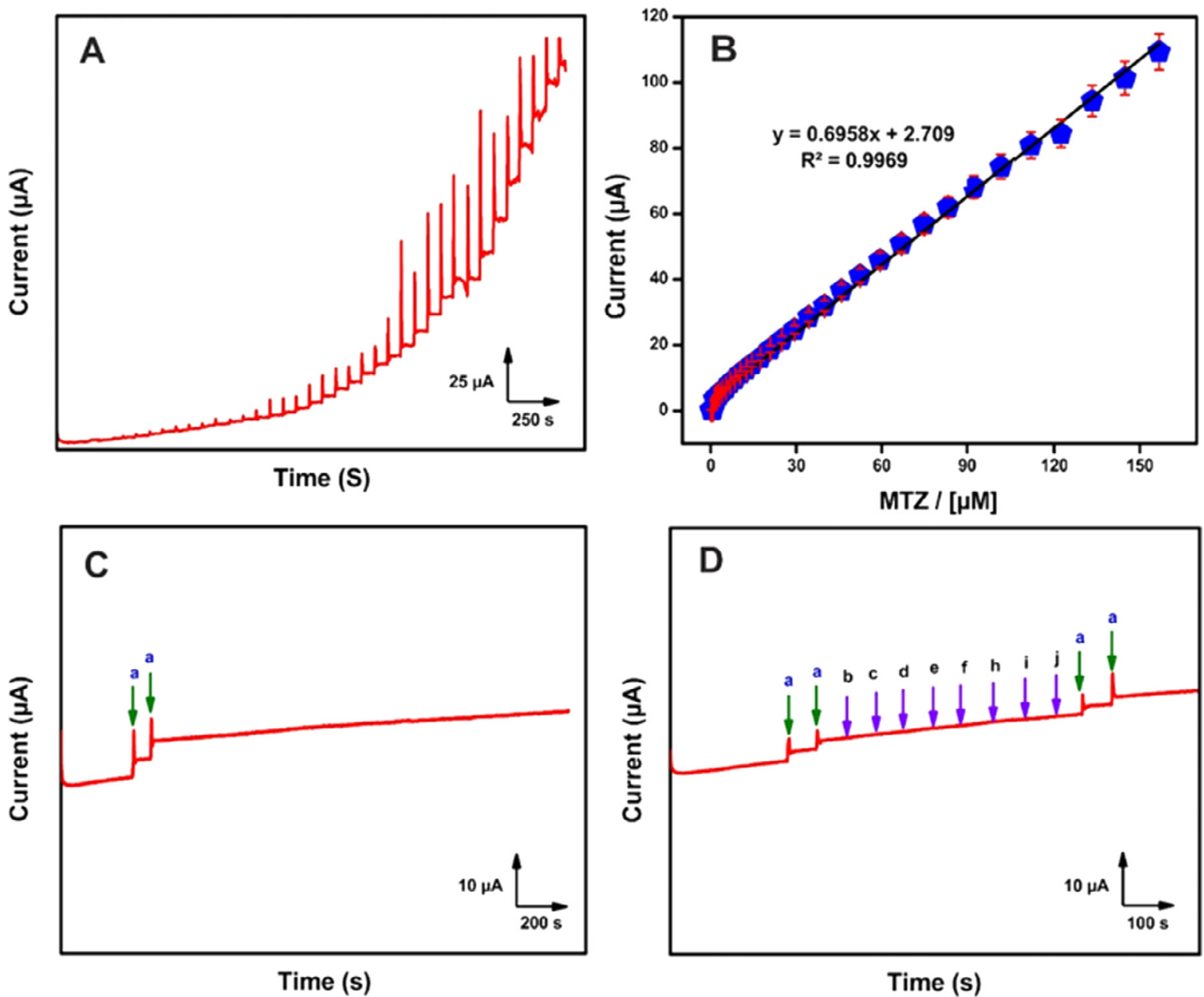

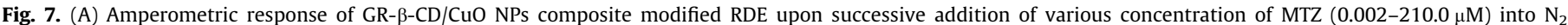

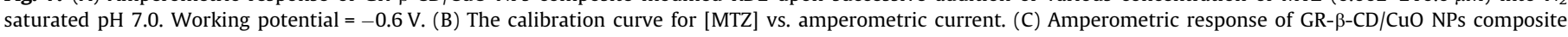

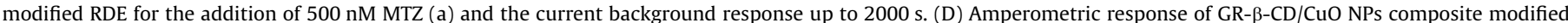

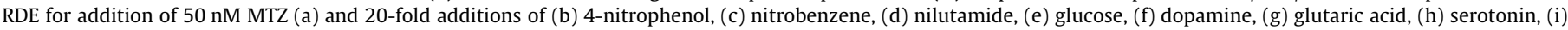
histidine and (j) flutamide.

estimated as $0.6 \mathrm{nM}$ based on $3 * \mathrm{Sd}$ of the blank response/slope of the calibration plot. The sensitivity of the sensor was $0.7 \mu \mathrm{A \mu M}^{-1}$ and was calculated from the slope of the calibration plot. To verify the novelty and advantage of the GR- $\beta-\mathrm{CD} / \mathrm{CuO}$ NPs composite modified electrode, the obtained analytical features (linear

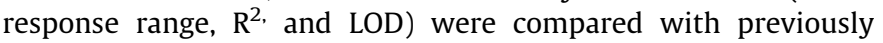
reported MTZ sensors. The comparative results are shown in Table 1 . The comparative results reveal that the LOD of the fabricated sensor $(0.6 \mathrm{nM})$ is much lower than previously reported MTZ sensors such as graphene-ionic liquid/GCE (47.0 nM) [30], activated GCE $(1.1 \mu \mathrm{M})$ [37], multiwalled carbon nanotubes/GCE (6 nM) [38], single wall carbon nanotubes/GCE (63.0 nM) [39], gold electrode (157.0 nM) and silver nanoparticles/sulfonate functionalized graphene/GCE (50.0 nM) [40]. In addition, the GR- $\beta-C D / C u O$ NPs composite modified electrode shows wider linear response range and appropriate $\mathrm{R}^{2}$ when compared to previously reported modified electrodes for determination of MTZ [27-30,37-41]. The result reveals that the GR- $\beta-\mathrm{CD} / \mathrm{CuO}$ NPs composite can be used as an advance electrode material for low-level detection of MTZ.

\subsection{Operational stability and selectivity of the sensor}

The operational stability of the GR- $\beta-\mathrm{CD} / \mathrm{CuO}$ NPs composite modified RDE for detection of $500 \mathrm{nM}$ MTZ was evaluated using amperometry. Fig. $7 \mathrm{C}$ shows the amperometric response of GR- $\beta$ $\mathrm{CD} / \mathrm{CuO} \mathrm{NPs}$ composite modified RDE for the addition of $500 \mathrm{nM}$ MTZ (curve a and b) into the constantly stirred $\mathrm{pH} 7.0$ and its related current response up to $2000 \mathrm{~s}$. Other experimental conditions are similar to Fig. 7A. It can be seen that a sharp amperomet-

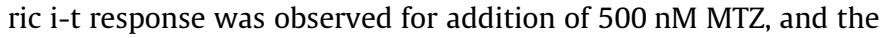
current response was almost unchanged up to $2000 \mathrm{~s}$. The result indicates that the excellent operational stability of the sensor. Selectivity of the electrode is more important to use for the practical applications, hence the GR- $\beta-\mathrm{CD} / \mathrm{CuO}$ NPs composite modified RDE was evaluated for detection of $50 \mathrm{nM}$ MTZ in the presence of 20 folds $(1.0 \mu \mathrm{M})$ addition of potentially active different interfering species. The amperometric i-t was used to evaluate the selectivity of the sensor, and the experimental conditions are similar to Fig. 7A. We have chosen a mixed range of interfering compounds such as nitro compounds (nitrobenzene and 4-nitrophenol), drugs (nilutamide and flutamide), amino acids, neurotransmitters, and sugars. The obtained selectivity results of the sensor are shown in Fig. 7D. It can be seen that the 20 folds addition of interference above compounds did not show any apparent response on GR- $\beta$ $\mathrm{CD} / \mathrm{CuO}$ NPs composite modified RDE. However, a clear and welldefined amperometric response was observed for the addition of $50 \mathrm{nM}$ MTZ. The high selectivity is possibly due to the lower working potential $(-0.6 \mathrm{~V})$ of the sensor than the tested interfering 
Table 1

Analytical comparison of GR- $\beta-\mathrm{CD} / \mathrm{CuO}$ NPs composite sensor with the previously reported sensors for the determination of MTZ.

\begin{tabular}{|c|c|c|c|c|c|}
\hline Sensor electrode & Detection method & $\mathrm{R}^{2}$ & $\mathrm{LOD}^{\mathrm{a}}(\mathrm{nM})$ & Linear range $(\mu \mathrm{M})$ & Ref. \\
\hline${ }^{1}$ Chit/CuTsPc/GCE & $\mathrm{DPV}^{\mathrm{b}}$ & 0.9976 & 0.41 & $0.008-0.72$ & {$[28]$} \\
\hline${ }^{2}$ MWCNTs/CTS-Ni/GCE & DPV & 0.0999 & 25.0 & $0.1-150.0$ & [29] \\
\hline${ }^{3} \mathrm{Gr}-\mathrm{IL} / \mathrm{GCE}$ & DPV & 0.9990 & 47.0 & $0.1-25.0$ & [30] \\
\hline${ }^{4}$ AGCE & DPV & 0.997 & 1100.0 & $2.0-600.0$ & [37] \\
\hline${ }^{5} \mathrm{MWCNT} / \mathrm{GCE}$ & DPV & 0.997 & 6.0 & $0.25-10.0$ & [38] \\
\hline${ }^{6}$ SWCNT/GCE & Amperometry & 0.9989 & 63.0 & $0.1-200.0$ & [39] \\
\hline${ }^{7} \mathrm{P}-\mathrm{AuE}$ & LSV $^{\mathrm{c}}$ & 0.9950 & 150.0 & $0.5-10.0$ & [40] \\
\hline${ }^{8} \mathrm{AgNPs} / \mathrm{SF}-\mathrm{GR} / \mathrm{GCE}$ & DPSV $^{d}$ & 0.9993 & 50.0 & $0.1-20.0$ & [41] \\
\hline GR- $\beta-\mathrm{CD} / \mathrm{CuO}$ NPs/GCE & Amperometry & 0.9969 & 0.6 & $0.002-210.0$ & This work \\
\hline
\end{tabular}

a Limit of detection.

b Differential pulse voltammetry.

c Linear sweep voltammetry.

d Differential pulse stripping voltammetry.

${ }^{1}$ Chitosan protected tetrasulfonated copper phthalocyanine thin-film modified glassy carbon electrode.

2 Multi-walled carbon nanotubes and chitosan-nickel complex modified glassy carbon electrode.

${ }^{3}$ Graphene and ionic liquid (1-butyl-3-methylimidazolium hexafluorophosphate) composite modified glassy carbon electrode.

4 Activated glassy carbon electrode.

5 Multi-walled carbon nanotube modified glassy carbon electrode.

${ }^{6}$ Single wall carbon nanotubes modified glassy carbon electrode.

7 Pretreated gold electrode.

${ }^{8}$ Silver nanoparticles/sulfonate functionalized graphene modified glassy carbon electrode.

Table 2

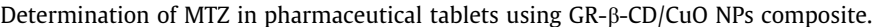
RSD is relative to the 3 measurements.

\begin{tabular}{lllll}
\hline Sample & Added $(\mu \mathrm{M})$ & Found $(\mu \mathrm{M})$ & Recovery $(\%)$ & RSD $(\%)$ \\
\hline A & 50.0 & 49.2 & 98.4 & 2.1 \\
B & 100.0 & 97.6 & 97.6 & 2.6 \\
C & 150.0 & 146.3 & 97.5 & 1.7 \\
\hline
\end{tabular}

compounds. The result authenticates that the GR- $\beta-\mathrm{CD} / \mathrm{CuO}$ NPs composite modified electrode can be used for the selective detection of MTZ.

\subsection{Determination of MTZ in pharmaceutical tablets}

To evaluate the practical feasibility sensor, the GR- $\beta-\mathrm{CD} / \mathrm{CuO}$ NPs composite was used for the determination of MTZ in MTZ containing pharmaceutical tablets ( $400 \mathrm{mg}$ ). Amperometric $i$ - $t$ method was used for the real sample analysis and standard addition method was used for the calculation of recovery of MTZ in pharmaceutical tablets. The desired concentration of MTZ tablet samples (stock solution) was prepared using pH 7.0. A known concentration MTZ containing tablet samples was used for real sample analysis. The obtained recovery values of MTZ in pharmaceutical tablets are summarized in Table 2 . It can be seen that the average recovery of MTZ in the real samples was $97.8 \%$ with the relative standard deviation (RSD) of $2.1 \%$ ( 3 measurements). The results indicate that the GR- $\beta-C D / C u O$ NPs composite modified electrode can be used for the precise practical determination of MTZ in real samples. The reusability of the GR- $\beta-\mathrm{CD} / \mathrm{CuO}$ NPs composite sensor was tested using cyclic voltammetry. The fabricated sensor was tested in 8 set of pH 7.0 containing $50 \mu \mathrm{M}$ MTZ samples at a scan rate of $50 \mathrm{mV} / \mathrm{s}$. The other experimental conditions are similar to Fig. 4A. The sensor shows the RSD of $2.9 \%$ for detection of 8 different MTZ containing $\mathrm{pH} 7.0$ samples. The result indicates that the high reusability of the GR- $\beta-\mathrm{CD} / \mathrm{CuO}$ NPs composite modified electrode towards the detection of MTZ.

\section{Conclusions}

In conclusion, a simple amperometric electrochemical sensor was fabricated using GR- $\beta-\mathrm{CD} / \mathrm{CuO}$ NPs composite modified electrode. The physicochemical characterizations confirmed the successful formation of GR- $\beta-C D$ CuO NPs composite and the existence of few-layered GR domains. Under optimized conditions, the fabricated sensor showed a wider linear range for the detection of MTZ with a lower LOD of $0.6 \mathrm{nM}$. The sensor showed advanced analytical performances towards detection of MTZ than previously reported GR and carbon nanomaterials based MTZ sensors. The sensor was highly selective and successfully applied for the practical determination of MTZ in pharmaceutical tablets. The discussed analytical features of the sensor authenticate that the sensor can be used for the real-time detection of MTZ in pharmaceutical and biological samples. As a future perspective, the synthesized GR- $\beta-C D / C u O$ NPs composite could be used for fabrication of other electrochemical sensors and biosensors.

\section{Conflicts of interest}

We confirm that there are no conflicts to declare.

\section{Acknowledgments}

The work was supported by the Engineering and Materials Research Centre (EMRC), School of Engineering, Manchester Metropolitan University, Manchester, UK. This work also jointly sponsored by the Ministry of Science and Technology (project No: 106-2119-M-027-001) of Taiwan. Authors also acknowledge the Precision analysis and Materials Research Center, National Taipei University of Technology for providing the all necessary Instrument facilities.

\section{References}

[1] X. Huang, X. Qi, Graphene-based composites, Chem. Soc. Rev. 41 (2012) $666-$ 686.

[2] E.P. Randviir, D.A.C. Brownson, C.E. Banks, A decade of graphene research: production, applications and outlook, Mater. Today 17 (2014) 426-432.

[3] W. Choi, I. Lahiri, R. Seelaboyina, Y.S. Kang, Synthesis of graphene and its applications: a review, Crit. Rev. Solid State Mater. Sci. 35 (2010) 52-71.

[4] B. Unnikrishnan, S. Palanisamy, S.M. Chen, A simple electrochemical approach to fabricate a glucose biosensor based on graphene-glucose oxidase biocomposite, Biosens. Bioelectron. 39 (2013) 70-75.

[5] T.B. Sarfraj, H. Mujawara, Q.T.T. Swapnil, B.A. Dai, S. Lee, W. Lee, S.H. Han, S.H Lee, Graphene/carbon nanotubes composites as a counter electrode for dyesensitized solar cells, Curr. Appl Phys. 12 (2012) e49-e53. 
[6] L. Song, C. Guo, T. Li, S. Zhang, C60/graphene/g- $C_{3} N_{4}$ composite photocatalyst and mutually- reinforcing synergy to improve hydrogen production in splitting water under visible light radiation, Ceram. Int. 43 (2017) 7901-7909.

[7] Q. Zhuo, Y. Ma, J. Gao, P. Zhang, Y. Xia, Y. Tian, X. Sun, J. Zhong, X. Sun, Facile synthesis of graphene/metal nanoparticle composites via self-catalysis reduction at room temperature, Inorg. Chem. 52 (2013) 3141-3147.

[8] S. Zhang, Y. Shao, H. Liao, J. Liu, I.A. Aksay, G. Yin, Y. Lin, Graphene decorated with PtAu alloy nanoparticles: facile synthesis and promising application for formic acid oxidation, Chem. Mater. 23 (2011) 1079-1081.

[9] Y. Guo, S. Guo, J. Ren, Y. Zhai, S. Dong, E. Wang, Cyclodextrin functionalized graphene nanosheets with high supramolecular recognition capability: synthesis and host-guest inclusion for enhanced electrochemical performance, ACS Nano 4 (2010) 4001-4010.

[10] P. Mahala, A. Kumar, S. Nayak, S. Behura, C. Dhanavantri, O. Jani, Graphene conducting polymer and their composites as transparent and curren spreading electrode in GaN solar cells, Superlattices Microstruct. 92 (2016) 366-373.

[11] H. Gómez, M.K. Ram, F. Alvi, P. Villalba, E. Stefanakos, A. Kumar, Grapheneconducting polymer nanocomposite as novel electrode for supercapacitors, J. Power Sources 196 (2011) 4102-4108.

[12] X. Wu, Y. Xing, D. Pierce, J.X. Zhao, One-pot synthesis of reduced graphene oxide/metal (oxide) composites, ACS Appl. Mater. Interfaces 9 (2017) 37962 37971.

[13] S.H. Choi, J.K. Lee, Y.C. Kang, Three-dimensional porous graphene-metal oxide composite microspheres: preparation and application in Li-ion batteries, Nano Res. 8 (2015) 1584-1594.

[14] Vellaichamy Balakumar, Periakaruppan Prakash, A facile in situ synthesis of highly active and reusable ternary Ag-PPy-GO nanocomposite for catalytic oxidation of hydroquinone in aqueous solution, J. Catal. 344 (2016) 795-805.

[15] Vellaichamy Balakumar, Periakaruppan Prakash, Silver nanoparticleembedded RGO-nanosponge for superior catalytic activity towards 4nitrophenol reduction, RSC Adv. 6 (2016) 88837-88845.

[16] Vellaichamy Balakumar, Periakaruppan Prakash, A facile, one-pot and ecofriendly synthesis of gold/silver nanobimetallics smartened rGO for enhanced catalytic reduction of hexavalent chromium, RSC Adv. 6 (2016) 57380-57388.

[17] B. Vellaichamy, P. Periakaruppan, S.K. Ponnaiah, A new in-situ synthesize ternary CuNPs-PANI-GO nano composite for selective detection of carcinogenic hydrazine, Sensors Actuat. B 245 (2017) 156-165.

[18] B. Vellaichamy, S.K. Ponnaiah, P. Periakaruppan, An in-situ synthesis of nove Au@NG-PPy nanocomposite for enhanced electrocatalytic activity toward selective and sensitive sensing of catechol in natural samples, Sensors Actuat. B 253 (2017) 392-399.

[19] S. Palanisamy, K. Thangavelu, S.M. Chen, V. Velusamy, M.H. Chang, T.W. Chen, F.M.A. Hemaid, M.A. Ali, S.K. Ramaraj, Synthesis and characterization of polypyrrole decorated graphene/ $\beta$-cyclodextrin composite for low level electrochemical detection of mercury (II) in water, Sens. Actuat., B 243 (2017) 888-894.

[20] G. Liu, B. Zheng, Y. Jiang, Y. Cai, J. Du, H. Yuan, D. Xiao, Improvement of sensitive CuO NFs-ITO nonenzymatic glucose sensor based on in situ electrospun fiber, Talanta 101 (2012) 24-31.

[21] X. Xiao, M. Wang, H. Li, Y. Pan, P. Si, Non-enzymatic glucose sensors based on controllable nanoporous gold/copper oxide nanohybrids, Talanta 125 (2014) 366-371.

[22] K.J. Choi, H.W. Jang, one-dimensional oxide nanostructures as gas-sensing materials: review, Sensors 10 (2010) 4083-4099.

[23] Y.Y. Yu, R.X. Xu, C. Gao, T. Luo, Y. Jia, J.H. Liu, X.J. Huang, novel 3D hierarchical cotton-candy-like CuO: surfactant-free solvothermal synthesis and application in As(III) removal, ACS Appl. Mater. Interfaces 4 (2012) 1954-1962.
[24] J. Liu, J. Jin, Z. Deng, S.Z. Huang, Z.Y. Hu, L. Wang, C. Wang, L.H. Chen, Y. Li, G.V. Tendeloo, B.L.J. Su, Tailoring $\mathrm{CuO}$ nanostructures for enhanced photocatalytic property, J. Colloid Interface Sci. 384 (2012) 1-9.

[25] N.C. Desai, A.S. Maheta, K.M. Rajpara, V.V. Joshi, H.V. Vaghani, H.M. Satodiya, Green synthesis of novel quinoline based imidazole derivatives and evaluation of their antimicrobial activity, J. Saudi Chem. Soc. 18 (2014) 963-971.

[26] A.H. Davies, J.A. Mafadzean, S. Squires, Treatment of vincent's stomatitis with metronidazole, Br. Med. J. 1 (1964) 1149.

[27] Y. Gu, X. Yan, C. Li, B. Zheng, Y. Li, W. Liu, Z. Zhang, Biomimetic sensor based on molecularly imprinted polymer with nitroreductase-like activity for metronidazole detection, Biosens. Bioelectron. 77 (2016) 393-399.

[28] S. Meenakshi, K. Pandian, L.S. Jayakumari, S. Inbasekaran, Enhanced amperometric detection of metronidazole in drug formulations and urine samples based on chitosan protected tetrasulfonated copper phthalocyanine thin-film modified glassy carbon electrode, Mater. Sci. Eng., C 59 (2016) 136144.

[29] A. Mao, H. Li, L. Yu, X. Hu, Electrochemical sensor based on multi-walled carbon nanotubes and chitosan-nickel complex for sensitive determination of metronidazole, J. Electroanal. Chem. 799 (2017) 257-262.

[30] J. Peng, C. Hou, X. Hu, Determination of metronidazole in pharmaceutical dosage forms based on reduction at graphene and ionic liquid composite film modified electrode, Sens. Actuat., B 169 (2012) 81-87.

[31] T.W. Chen, S. Palanisamy, S.M. Chen, V. Velusamy, K.K. Ramasubbu, S.K. Ramaraj, A novel non-enzymatic glucose sensor based on melamine supported CuO nanoflakes modified electrode, Adv. Mater. Lett. 8 (2017) 852-856.

[32] Z.S. Wu, W. Ren, D.W. Wang, F. Li, B. Liu, H.M. Cheng, High-energy $\mathrm{MnO}_{2}$ nanowire/graphene and graphene asymmetric electrochemical capacitors, ACS Nano 4 (2010) 5835-5842.

[33] L. Xu, C. Srinivasakannan, J. Peng, L. Zhang, D. Zhang, Synthesis of Cu-CuO nanocomposite in microreactor and its application to photocatalytic degradation, J. Alloys Compd. 695 (2017) 263-269.

[34] S. Palanisamy, P.Y. Fan, S.M. Chen, V. Velusamy, J.M. Hall, Facile preparation of a cellulose microfibers-exfoliated graphite composite: a robust sensor for determining dopamine in biological samples, Cellulose 24 (2017) 4291-4302.

[35] D.A.C. Brownson, S.A. Varey, F. Hussain, S.J. Haigh, C.E. Banks, Electrochemical properties of CVD grown pristine graphene: monolayer- vs. quasi-graphene, Nanoscale 6 (2014) 1607-1621.

[36] S. Palanisamy, T. Kokulnathan, S.M. Chen, V. Velusamy, S.K. Ramaraj, Voltammetric determination of Sudan I in food samples based on platinum nanoparticles decorated on graphene- $\beta$-cyclodextrin modified electrode, J. Electroanal. Chem. 794 (2017) 64-70.

[37] A. Ozkan, Y. Ozkan, Z. Senturk, Electrochemical reduction of metronidazole at activated glassy carbon electrode and its determination in pharmaceutical dosage forms, J. Pharm. Biomed. Anal. 17 (1998) 299-305.

[38] S. Lü, K. Wu, X. Dang, S. Hu, Electrochemical reduction and voltammetric determination of metronidazole at a nanomaterial thin film coated glassy carbon electrode, Talanta 63 (2004) 653-657.

[39] A. Salimi, M. Izadi, R. Hallaj, M. Rashidi, Simultaneous determination of ranitidine and metronidazole at glassy carbon electrode modified with single wall carbon nanotubes, Electroanalysis 19 (2007) 1668-1676.

[40] A. Rezaei, S. Damiri, Fabrication of a nanostructure thin film on the gold electrode using continuous pulsed-potential technique and its application for the electrocatalytic determination of metronidazole, Electrochim. Acta 55 (2010) 1801-1808.

[41] H.Y. Zhai, Z.X. Liang, Z.G. Chen, Simultaneous detection of metronidazole and chloramphenicol by differential pulse stripping voltammetry using a silver nanoparticles/sulfonate functionalized graphene modified glassy carbon electrode, Electrochim. Acta 171 (2015) 105-113. 